\title{
PENANGGULANGAN BENCANA BANJIR DI SUNGAI BATANG MERAO PADA BADAN PENANGGULANGAN BENCANA DAERAH KOTA SUNGAI PENUH TAHUN 2019
}

\author{
NANIK MANDASARI, S.IP., M.Si \\ STIA Nusantara Sakti Sungai Penuh
}

mandasarinanik@gmail.com

\begin{abstract}
ABSTRAK
Analysis of Flood Disaster Management in Batang Merao River at Sungai Penuh Regional Disaster Management Agency. Flooding is an event where land which is usually dry (not swampy areas) becomes inundated by water, this is caused by high rainfall and topographic conditions in the form of lowlands to sunken areas. In addition, the occurrence of flooding can also be caused by runoff which overflows and its volume exceeds the drainage capacity of the drainage system or river flow system. The occurrence of flood disasters is also caused by the low ability of soil infiltration, so that the soil is no longer able to absorb water. Flooding can occur due to rising water levels due to rainfall above normal, changes in temperature, embankments / dams that break, fast melting snow, obstructed water flow in other places. The purpose of this research is to find out how the Flood Disaster Management in Batang Merao River in Sungai Penuh City Regional Disaster Management Agency. This study uses a qualitative approach that examines an object of research by studying in its entirety and in depth rather than looking at the relationship of two or more variables, where the results of the study will be processed based on the interpretive researcher and described in a descriptive form. Data obtained through field interviews with 7 informants namely 1 key informant and 6 ordinary informants. Flood mitigation consists of prevention and mitigation, preparedness, emergency response and rehabilitation and reconstruction. Based on the existing work program, all activities have been carried out by the Sungai Penuh City Regional Disaster Management Agency in flood mitigation in Sungai Merao River Sungai Penuh which is guided by Law Number 24 Year 2007.
\end{abstract}

Keywords : Flood Disaster Managemen.

\section{ABSTRAK}

Banjir merupakan peristiwa dimana daratan yang biasanya kering (bukan daerah rawa) menjadi tergenang oleh air, hal ini disebabkan oleh curah hujan yang tinggi dan kondisi topografi wilayah berupa dataran rendah hingga cekung. Selain itu, terjadinya banjir juga dapat disebabkan oleh limpasan air permukaan (runoff) yang meluap dan volumenya melebihi kapasitas pengaliran sistem drainase atau sistem aliran sungai.Terjadinya bencana banjir juga disebabkan oleh rendahnya kemampuan infiltrasi tanah, sehingga menyebabkan tanah tidak mampu lagi menyerap air. Banjir dapat terjadi akibat naiknya permukaan air lantaran curah hujan yang diatas normal, perubahan suhu, tanggul/bendungan yang bobol, pencairan salju yang cepat, terhambatnya aliran air di tempat lain. Tujuan penelitian untuk mengetahui bagaimana Penanggulangan Bencana Banjir di Sungai Batang Merao Pada Badan Penanggulangan Bencana Daerah Kota Sungai Penuh. Penelitian ini menggunakan pendekatan kualitatif yaitu meneliti suatu objek penelitian dengan mengkaji secara keseluruhan dan mendalam bukan melihat hubungan dua variabel atau lebih, dimana hasil penelitian akan diolah berdasarkan interpretatif peneliti dan diuraikan dalam bentuk deskriptif. Data diperoleh melalui wawancara dilapangan kepada 7 orang informan yakni 1 orang informan kunci dan 6 orang informan biasa. Penanggulangan banjir terdiri dari pencegahan dan mitigasi, kesiapsiagaan, tanggap 
darurat serta rehabilitasi dan rekonstruksi. Berdasarkan program kerja yang ada, segala kegiatan telah dilaksanakan oleh Badan Penanggulangan Bencana Daerah Kota Sungai Penuh dalam penanggulangan banjir di Sungai Batang Merao Kota Sungai Penuh yang berpedoman pada Undang-undang Nomor 24 Tahun 2007.

\section{Kata kunci : Penanggulangan Bencana Banjir}

\section{PENDAHULUAN}

Banjir merupakan luapan air yang melebihi tinggi muka air normal sehingga meluap dari palung sungai yang menyebabkan genangan pada lahan rendah di sisi sungai.Lazimnya banjir disebabkan oleh curah hujan yang tinggi diatas normal.Akibatnya, sistem pengaliran air yang terdiri dari sungai dan anak sungai serta sistem saluran drainase dan kanal penampung banjir buatan yang ada tidak mampu menampung akumulasi air hujan sehingga meluap.

Yang menjadi Fenomena dalam penelitian ini adalah :

1. Tiap Tahun di wilayah Sungai Batang Merao Kota Sungai Penuh Sering Terjadi Banjir.

2. Pemerintah Kota Sungai Penuh melalui Badan penanggulangan Bencana Daerah Kota Sungai Penuh Belum Berhasil Sepenuhnya membebaskan banjir di sekitar wilayah Sungai Batang Merao Kota Sungai Penuh.

3. Di Kota Sungai Penuh sering di landa Banjir khususnya pada Sungai Batang Merao, faktor penyebab air sungai meluap adalah tingginya intensitas hujan terutama di hulu sungai.

4. Badan Penanggulangan Bencana Daerah Kota Sungai Penuh Belum berperan secara optimal, baik secara langsung maupun tidak langsung dalam penyelenggaraan penanggulangan bencana Banjir.

Untuk mengantisipasi dampak kepada masyarakat akibat kondisi yang buruk akibat bencana banjir diperlukan adanya kesiapsiagaan dalam rangka meminimalisirkan dampak yang akan terjadi. Dalam meminimalisirkan dampak akibat bencana banjir, BPBD kota Sungai Penuh merupakan lini terdepan dalam mengendalikan dan menanggulangi resiko dan dampak bencana, terutama banjir.

Masalah sarana dan prasarana penunjang perlu diperhatikan karena akan berkaitan dengan aktivitas dan mobilitas kerja dari BPBD Kota Sungai penuh .Tanpa adanya sarana dan prasarana yang memadai, maka penyelenggaraan penanggulangan bencana banjir belum optimal dilakukan. Selain itu BPBD Kota Sungai penuh kekurangan orang yang kompeten di bidangnya hal ini dikarenakan BPBD memberikan pelayanan 24 jam non stop kepada masyarakat, sedangkan pegawai yang jaga dibagi per shift menjadi 8 orang hal ini membuat pelayanan yang diberikan kurang efisien, kurang efektif, dan kurang cepat tanggap. Hal ini akan berpengaruh terhadap kualitas layanan yang diberikan oleh BPBD Kota Sungai penuh.

Capaian kinerja BPBD Kota Sungai Penuh dapat kita lihat pada kegiatan atau program BPBD yang tidak mencapai target disetiap tahapan bencana yaitu pada tahap tanggap darurat yaitu menyelenggarakan pengadaan logistic dan obat-obatan bagi penduduk di penampungan sementara, dimana 2015 hanya tercapai 99,04\%, ditahun 2016 mengalami kenaikan menjadi 99,40\%, di tahun 2017 mengalami menurun ke 99,22\%, di tahun 2018 kembali mengalami penurunan menjadi 98,95, ditahun 2019 juga mengalami penurunan menjadi 98,37\% jauh dari target $100 \%$ yang ingin dicapai oleh BPBD, hal ini disebabkan oleh lebih banyak kebutuhan masyarakat dari pada ketersediaan logistik yang ada, selain itu karena dana yang dimiliki oleh BPBD yang minim. (Diolah dari Laporan 
Kinerja Satuan Perangkat Daerah Tahun Anggaran 2015-2019 Badan Penanggulangan Bencana Daerah Kota Sungai Penuh per 31 Desember 2019). Hal ini membuktikan bahwa kinerja BPBD dalam penanggulangan banjir belum maksimal dilakukan karena masih terdapat kendala dalam mencapai kinerja yang lebih baik dan masih tingginya bencana banjir di tahun 2019 yaitu 20 kejadian banjir.

Namun demikian pada dasarnya kesiapsiagaan bukan hanya terfokus pada kegiatankegiatan penyaluran bantuan logistic, tetapi kegiatan kesiapsiagaan hendaknya didasarkan kepada kepentingan masyarakat secara menyeluruh dalam pengendalian dampak bencana banjir dengan memperhatikan kesehatan dan keselamatan, fasilitas dan infrastuktur, pemberiyan pelayanan, dan kondisi lingkungan dan ekonomi masyarakat korban. Kesiapsiagaan juga terfokus pada upaya-upaya pencegahan pihak terkait dalam meminimalisir dampak yang mungkin akan dirasakan masyarakat yang sering mengelami bencana banjir tersebut. Sehingga menjadi keseharusan pihak seperti BPBD untuk mempersiapkan segala prasarana dan sarana guna meminimalisir segala dampak banjir tersebut. Pada tahun 2019 dikota sungai penuh khususnya di sungai batang merao, yang sering terkena banjir dapat kita lihat pada tabel dibawah ini :

Tabel 1.1

Laporan Kejadian Bencana Banjir Kota Sungai Penuh

\begin{tabular}{|c|c|c|c|c|}
\hline No & Hari/Tgl & Desa & $\begin{array}{l}\text { Jumlah Kartu } \\
\text { Keluarga (KK) }\end{array}$ & Dampak \\
\hline 1 & $\begin{array}{l}3 \text { Maret } \\
2019\end{array}$ & $\begin{array}{l}\text { Tanjung, } \quad \text { Kec.Hamparan } \\
\text { Rawang }\end{array}$ & - & $\begin{array}{l}\text { - sebagian rumah masyarakat tengenang air } \\
\text { - jebolnya tanggul }\end{array}$ \\
\hline 2 & $\begin{array}{l}18 \text { Maret } \\
2019\end{array}$ & $\begin{array}{l}\text { Kec. Hamparan Rawang } \\
\text { Desa Air Sempit }\end{array}$ & - & - Rumah Masyarakat Terendam Banjir \\
\hline 3 & $\begin{array}{l}\text { 18 Maret } \\
2019\end{array}$ & Kec. Tanah Kampung & - & - Rumah masyarakat terendam banjir \\
\hline 4 & $\begin{array}{l}21 \text { Maret } \\
2019\end{array}$ & $\begin{array}{l}\text { Desa Tanjung, Kec. } \\
\text { Hamparan Rawang }\end{array}$ & - & 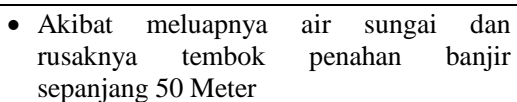 \\
\hline 5 & $\begin{array}{l}30 \text { Okt } \\
2019\end{array}$ & Kec. Hamparan Rawang & - & $\begin{array}{l}\text { - Akibat meluapnya air sungai dan } \\
\text { mengakibatkan air mengenangi jalan dan } \\
\text { rumah masyarakat }\end{array}$ \\
\hline 6 & $\begin{array}{c}31 \text { Okt } \\
2019\end{array}$ & $\begin{array}{l}\text { Desa koto tuo, Kec. Tanah } \\
\text { Kampung }\end{array}$ & - & $\begin{array}{l}\text { - Rumah masyarakat terkena banjir dan } \\
\text { sawah-saah terendam banjir }\end{array}$ \\
\hline 7 & $\begin{array}{c}02 \mathrm{Nov} \\
2019\end{array}$ & $\begin{array}{l}\text { Kec. Tanah Kampung } \\
\text { (Tanjung karang dan Koto } \\
\text { pudung) }\end{array}$ & - & $\begin{array}{l}\text { - Rumah masyarakat terkena banjir dan } \\
\text { sawah-saah terendam banjir }\end{array}$ \\
\hline 8 & $\begin{array}{c}2 \mathrm{Nov} \\
2019\end{array}$ & $\begin{array}{l}\text { Desa Tanjung Muda, Kec. } \\
\text { Hamparan Rawang }\end{array}$ & $430 \mathrm{KK}$ & - Mengakibatkan rusaknya akses jalan desa \\
\hline 9 & $\begin{array}{c}02 \mathrm{Nov} \\
2019\end{array}$ & $\begin{array}{l}\text { Desa Koto Tengah, Kec. } \\
\text { Tanah Kampung }\end{array}$ & $43 \mathrm{KK}$ & $\begin{array}{l}\text { - Perumahan masyarakat terendam banjir } \\
\text { dan sawah-saah tersebut terendam banjir }\end{array}$ \\
\hline 10 & $\begin{array}{l}02 \mathrm{Nov} \\
2019\end{array}$ & $\begin{array}{l}\text { Desa Tanjung Bunga, Kec. } \\
\text { Tanah Kampung }\end{array}$ & $220 \mathrm{KK}$ & $\begin{array}{l}\text { - Rumah masyarakat terkena banjir dan } \\
\text { sawah-sawah terendam banjir }\end{array}$ \\
\hline 11 & $\begin{array}{c}02 \mathrm{Nov} \\
2019 \\
\end{array}$ & $\begin{array}{l}\text { Desa Tanjung Karang, } \\
\text { Kec. Tanah Kampung }\end{array}$ & $153 \mathrm{KK}$ & $\begin{array}{l}\text { - Rumah masyarakat terkena banjir dan } \\
\text { sawah-sawah terendam banjir }\end{array}$ \\
\hline 12 & $\begin{array}{l}02 \mathrm{Nov} \\
2019\end{array}$ & Desa Koto Pudung & - & $\begin{array}{l}\text { Terendamnya rumah Masyarakat dan } \\
\text { sawah-sawah masyarakat }\end{array}$ \\
\hline 13 & $\begin{array}{c}02 \mathrm{Nov} \\
2019 \\
\end{array}$ & Desa Tanjung Karang & $195 \mathrm{KK}$ & $\begin{array}{l}\text { - Curah hujan yang tinggi menyebabkan } \\
\text { meluapnya sungai batang merao }\end{array}$ \\
\hline 14 & $\begin{array}{l}03 \text { Nov } \\
2019\end{array}$ & $\begin{array}{l}\text { Desa Koto Tua, Kec Tanah } \\
\text { Kampung }\end{array}$ & $246 \mathrm{KK}$ & $\begin{array}{l}\text { - Rumah masyarakat terkena banjir dan } \\
\text { sawah-sawah terendam banjir }\end{array}$ \\
\hline 15 & $\begin{array}{c}06 \text { Des } \\
2019\end{array}$ & Desa Koto Pudung & - & $\begin{array}{l}\text { - Curah hujan yang tinggi menyebabkan } \\
\text { tengenangnya air dihalaman dan jalan } \\
\text { masyarakat }\end{array}$ \\
\hline
\end{tabular}


Badan Penanggulangan Bencana Daerah Kota Sungai Penuh tiap tahun terus berupaya dalam melaksanakan Penanggulangan Banjir di Kota Sungai Penuh kususnya pada Sungai Batang Merao. Upaya mengantisipasi dan mencegah potensi bencana banjir di Sungai Batang Merao Kota Sungai Penuh dibutuhkan peran dan sikap bersama Pemerintah, Lembaga atau Organisasi Kemasyarakatan, Dunia Usaha, dan Masyarakat. Setiap pihak dapat memberikan kontribusi pelayanan terhadap ancaman bencana, yang sangat dibutuhkan perannya dalam upaya penanggulangan bencana adalah Badan Penanggulangan Bencana Daerah (BPBD) Kota Sungai Penuh. Akan tetapi dalam perjalanannya Badan Penanggulangan Bencana Daerah (BPBD) Kota Sungai Penuh sejak tahun 2012 sampai 2018 awal masih minim program kerja, hal ini juga dapat dilihat pada saat banjir yang melanda Sungai Batang Merao pada tanggal 06 januari 2018 yang merusak hampir 1/3 daerah pertanian. Proses tanggap darurat dan pasca banjir tidak dijalankan dengan baik, tidak juga melaksanakan perbaikan infrastruktur akibatnya tahun 2018 Masyarakat daerah sekitar Sungai Batang Merao masih belum terbebas dari banjir. Hal ini cukup menjelaskan bahwa Pemerintah Kota dan BPBD Kota Sungai Penuh belum maksimal dalam Penanggulangan Banjir. Sehingga wajar apabila Kota Sungai Penuh dijuluki dengan kawasan rawan banjir. Keberhasilan program dalam sebuah pekerjaan tidak akan menjadi efektif dan efisien apabila tidak ditunjang dan diimbangi dengan pelayanan yang diberikan berdasarkan tugas, pokok dan fungsi.

Berdasarkan uraian diatas, peneliti tertarik untuk melakukan penelitian tentang "Analisis Penanggulangan Bencana Banjir Disungai Penuh Batang Merao Pada Badan Penanggulangan Bencana Daerah Kota Sungai Penuh". Dari latar belakang atau fenomena diatas dapat penulis simpulkan rumusan masalah pada penulisan ini adalah "Bagaimanakah Penanggulangan Bencana Banjir di Sungai Batang Merao Pada Badan Penanggulangan Bencana Daerah Kota Sungai Penuh?”

\section{METODE PENELITIAN}

Dalam penelitian ini peneliti menggunakan pendekatan kualitatif. Menurut Moleong (2009:21) pendekatan kualitatif yaitu meneliti suatu objek penelitian dengan mengkaji secara keseluruhan dan mendalam bukan melihat hubungan dua variabel atau lebih, dimana hasil penelitian akan diolah berdasarkan interpretatif peneliti dan diuraikan dalam bentuk deskriptif

Penelitian ini bertujuan untuk mendapatkan gambaran tentang Analisis Sistem Pengelolaan Dana Bantuan Banjir Oleh Badan Penanggulangan Bencana Daerah (BPBD) Tahun 2018 di Kota Sungai Penuh. Data yang hendak dikumpulkan adalah tentang perencanaan, pengorganisasian, pelaksanaan, pengontrolan atau pengawasan. Dengan demikian, penelitian ini lebih sesuai menggunakan metode penelitian kualitatif dengan latar belakang untuk mendapatkan pemahaman dan penafsiran yang mendalam mengenai makna, fakta yang menyeluruh tentang Analisis Sistem Pengelolaan Dana Bantuan Banjir Oleh Badan Penanggulangan Bencana Daerah (BPBD) Tahun 2019 .

Adapun secara fokus penelitian bahwa batasan penelitian yang diteliti olehpeneliti melingkupi pelaksanaan atau implementasi atas tugas pokok dan fungsi yangdilakukan oleh Badan Penanggulangan Bencana Daerah (BPBD) Kota Sungai Penuh terhadap bencana banjir. Hal ini mencakup usaha implementasi pencegahan, penanganan tanggap darurat, rehabilitasi dan rekontruksi bencana banjir yangdilakukan sehingga fokus penelitian yang diteliti berupa Analisis Sistem Penanggulangan Bencana Banjir oleh Badan Penanggulangan Bencana Daerah (BPBD) di Kota Sungai Penuh. 
Penanggulangan bencana banjir oleh Badan Penanggulangan Bencana Daerah (BPBD) di Kota Sungai Penuh dapat diartikan sebagai pelaksanaan pencegahan, penanganan darurat, rehabilitasi dan rekontruksi yang dilakukan oleh BPBD Kota Sungai Penuh dalam melaksanakan tugas dan fungsinya dalam pencegahan dan penanganan bencana banjir di Kota Sungai Penuh.

Adapun aspek-aspek penelitian yang diteliti pada penelitian ini diambil dari tugas pokok dan fungsi yang tertuang dalam Pasal 3 PERDA Nomor 03 tahun2010 tentang Badan Penanggulangan Bencana Daerah Kota Sungai Penuh. Adapun aspektersebut ialah sebagai berikut :

1. Pencegahan Bencana Banjir

2. Penanganan Darurat Bencana Banjir

3. Rehabilitasi dan Rekonstruksi bencana banjir.

Penelitian ini menggunakan teknik pengumpulan data primer dan teknik pengumpulan data skunder. Teknik pengumpulan data primer diperoleh dari :

a. Observasi

b. Wawancara

c. Dokumentasi

Berdasarkan tujuan penelitian yakni untuk mengetahui bagaimanakah Analisis Penanggulangan Bencana Banjir di Sungai Batang Merao Pada Badan Penanggulangan Bencana Daerah Kota Sungai Penuh, maka metode analisis data yang digunakan dalam penelitian ini adalah metode deskriptif yaitu data yang diperoleh dilapangan kemudian diolah dengan menggunakan interpretative peneliti untuk mengolah data mentah yang relevan yang diperoleh dilapangan kemudian hasil penelitian diuraikan dalam bentuk kalimat bukan angka-angka atau data statistik

Setelah data dan informasi dikumpulkan dan diolah serta untuk menjaga validitas data maka dilakukan triangulasi baik terhadap data, sumber maupun metode.

a. Triangulasi sumber, dilakukan dengan cara :

b. Triangulasi data, dilakukan dengan cara :

c. Triangulasi metode, dilakukan dengan cara :

Analisis data terdiri dari tiga alur kegiatan yang terjadi secara bersamaan yaitu:

a. Reduksi Data

b. Penyajian (display) data

c. Penarikan kesimpulan (verifikasi) data

\section{HASIL DAN PEMBAHASAN}

Badan Penanggulangan Bencana Daerah merupakan salah satu instansi yang melaksanakan penanggulangan bencana yang ada di Kota Sungai Penuh termasuk penanggulangan bencana banjir. Dalam hal ini, penanggulangan bencana yang dilaksanakan oleh instansi pemerintah tersebut ialah dengan melakukan pencegahan, penanganan darurat, rehabilitasi dan rekonstruksi. Penanggulangan bencana banjir dimaksudkan agar dapat meminimalisir kerusakan dan memberikan kenyamanan warga dalam bertempat tinggal. Dengan pentingnya penanggulangan tersebut peneliti meneliti mengenai Analisis Penanggulangan bencana banjir oleh Badan Penanggulangan Bencana Daerah (BPBD) Kota Sungai Penuh.Untuk menganalisis tersebut, peneliti menggunakan empat aspek yaitu Pencegahan Bencana Banjir, Penanganan Darurat Bencana Banjir, Rehabilitasi bencana banjir, Rekonstruksi Bencana Banjir. 


\section{Pencegahan dan Mitigasi}

Berdasarkan wawancara peneliti dengan informan tentang pencegahan dapat diketahui bahwa pencegahan merupakan upaya yang dilakukan oleh manusia pada tahap pra bencana yang paling utama dilaksanakan, dimana bertujuan untuk menghilangkan ancaman banjir.

Mitigasi adalah upaya yang dilakukan oleh manusia pada tahap pra bencana yang lebik terfokus pada pengurangan skala dan besaran intensitas sebuah ancaman banjir. Dari Hasil Wawancaraas dapat disimpulkan bahwa mitigasi sangat diperlukan sebagai informasi awal bagi masyarakat yang berada di kawasan rawan bencana untuk mengantisipasi sebelum terjadi bencana.

\section{Kesiapsiagaan}

Berdasarkan wawancara peneliti dengan informan tentang kesiapsiagaan dapat diinterpretasikan kegiatan kesiapsiagaan merupakan langkah penting dalam upaya penanggulangan banjir karena tidak semua bahaya dapat dicegah ataupun ditangani dengan aktivitas pencegahan dan mitigasi. Kegiatan kesiapsiagaan merupakan rencana cadangan dan tindakan antisipatif jika suatu saat banjir benar-benar terjadi.

\section{Tanggap Darurat Bencana}

Berdasarkan wawancara peneliti dengan informan tentang tanggap darurat dapat diinterpretasikan bahwa tanggap darurat adalah serangkaian kegiatan BPBD Kota Sungai Penuh yang dilakukan oleh para pegawai dan Team Reaksi Cepat segera setelah kejadian banjir. Tanggap darurat umumnya berkisar dari menyediakan bantuan spesifik namun terbatas seperti membantu evakuasi dan transportasi para pengungsi, hunian darurat, makanan dan bantuan kesehatan.

\section{Rehabilitasi dan Rekonstruksi}

Berdasarkan jawaban informan dari wawancara dapat diketahui bahwa kegiatan rehabilitasi merupakan kegiatan yang menghubungkan antara tanggap darurat dengan pasca bencana yang bertujuan membantu masyarakat korban banjir untuk mengembalikan kehidupan masyarakat pada wilayah pasca banjir yang bersifat segera.

Dari hasil wawancara diatas dapat disimpulkan Rekonstruksi merupakan upaya yang dilakukan oleh BPBD Kota Sungai Penuh untuk memulihkan infrastruktur masyarakat yang ada pada wilayah pasca banjir. Pembangunan kembali infrastrukstur merupakan rencana jangka panjang dengan tujuan pembangunan menyeluruh agar lebih baik dan ancaman serupa tidak terulang kembali.

\section{PEMBAHASAN}

Badan Penanggulangan Bencana Daerah merupakan salah satu instansi yangmelaksanakan penanggulangan bencana yang ada di Kota Sungai Penuh termasukpenanggulangan bencana banjir.Dalam hal ini, penanggulangan bencana yangdilaksanakan oleh instansi pemerintah tersebut ialah dengan melakukan pencegahan,penanganan darurat, rehabilitasi dan rekonstruksi.Penanggulangan bencana banjirdimaksudkan agar dapat meminimalisir kerusakan dan memberikan kenyamananwarga dalam bertempat tinggal. Dengan pentingnya penaggulangan tersebut penelitimeneliti mengenai Analisis Penanggulangan bencana banjir oleh Badan Penanggulangan Bencana Daerah (BPBD) Kota Sungai Penuh.Untuk menganalisistersebut, peneliti menggunakan empat aspek yaitu Pencegahan Bencana Banjir,Penanganan Darurat Bencana Banjir, Rehabilitasi bencana banjir, Rekonstruksi Bencana Banjir.

Dari hasil penelitian mengenai pencegahan bencana banjir yang dilaksanakanoleh instansi BPBD Kota Sungai Penuh di temukan berbagai kendala dalam pelaksanaanpencegahan bencana banjir. Adapun dalam segi pemantauan rutin yang dilaksanakanoleh BPBD belum optimal hal ini terlihat belum adanya laporan pemantauan dalamsegi administrasi juga belum adanya pos jaga serta 
laporan pemantauan dari satgasyang menjaga di kawasan bencana alam. Seharusnya di banyun pos jaga di tiapkecamatan guna untuk melakukan pemantauan rutin terhadap kawasan yang seringterkena banjir. Indikator lain seperti halnya pelaksanaan pembuatan peta rawan bencana khususnya bencana banjir yang belum ada sehingga instansi BPBD belum dapat menyampaikan informasi rawan bencana di kawasan Kota Sungai Penuh dan juga pelaksanaan pelatihan kesigapan dalam pencegahan dan penanganan bencana belum dirasakan seutuhnya oleh masyarakat di buktikan dengan pelatihan yang dilakukan tidak berkelanjutan serta pelatihan yang dilakukan belum merata didapatkan atau dirasakan oleh seluruh masyarakat di kawasan bencana banjir khususnya sehingga dalam hal ini dapat dikatakan bahwa pelaksanaan pencegahan yang dilakukan oleh BPBD Kota Sungai Penuh belum berjalan sebagaimana mestinya. Selain itu perlunya diadakan sosialisasi dengan metode berbeda agar dapat dipahami dan diterapkan oleh masyarakat di Kota Sungai Penuh.

Dari penanganan darurat bencana banjir dapat disimpulkan bahwa pelaksanaan penanganan darurat bencana telah berjalan akan tetapi belum terlaksana sebagaimana yang diharapkan oleh masyarakat di KotaSungai Penuh. Permasalahan yang sering terjadi seperti personil yang belum terlihat membantu masyarakat saat terjadi bencana banjir, hal ini mengakibatkan keterlambatan dalam mengurangi resiko bencana banjir.Seharusnya dari instansi BPBD perlu menambahkan jumlah personil atau satgas serta melakukan pelatihan dalam meningkatiak kapasitas dan kualitas personil. Selain dari itu,peralatan yang belum memada, sarana dan prasarana sewaktu terjadinya banjir belum sepenuhnya ada seperti tenda yang masih kurang perahu karet banyak yang rusak serta peralatan lain yang belum ada sehingga menghambat alannya penanganan bencana banjir di Kota Sungai Penuh.

Dari hasil penelitian mengenai penanganan banjir melalui rehabilitasi dan rekontruksi yang dilaksanakan oleh instansi BPBD Kota Sungai Penuh di temukan berbagai kendala dalam pelaksanaan pencegahan bencana banjir. Permasalahan yang sering terjadi seperti Koordinasi yang dijalankan antara pemerintah dan masyarakat belum berjalan dengan baik dan optimal guna menentukan titik rawan bencana sehingga masih sulit untuk melakukan perehaban pasca bencana banjir, Masih banyak bangunan-bangunan yang lama belum di lakukan perehapan seperti tanggul dan gorong-gorong yang mengakibatkan jebolnya tanggul tersebut.Pelaksanaan rekostruksi dan rehabilitasi belum merata dan ada beberapa titik belum di rehabilitasi atau di lakukan rekonstruksi.

\section{KESIMPULAN}

Berdasarkan penelitian yang telah peneliti lakukan dan dituangkan dalam skripsi ini dapat diambil kesimpulan sebagai berikut:

1. Pencegahan. Terlaksananya program kerja sosialisasi dan simulasi banjir untuk masyarakat sekitar wilayah Sungai Batang Merao Kota Sungai Penuh.

Mitigasi.BPBD Kota Sungai Penuh telah berupaya dalam pemberian informasi tentang bencana banjir untuk masyarakat sekitar wilayah Sungai Batang Merao Kota Sungai Penuh.

2. Kesiapsiagaan. Pembentukan Team Reaksi Cepat (TRC) yang telah dibekali dengan berbagai pendidikan dan pelatihan.

3. Tanggap Darurat Bencana. Ketersediaan bantuan makanan dan pendirian posko bencana serta hunian darurat untuk korban banjir di sekitar wilayah Sungai Batang Merao Kota Sungai Penuh.

4. Rehabilitasi. Belum banyak upaya yang dilakukan oleh BPBD Kota Sungai Penuh pada kegiatan rehabilitasi dalam penanggulangan banjir di Sungai Batang Merao Kota Sungai Penuh.

Rekonstruksi. Pemberian bantuan bahan bangunan untuk merekonstruksi rumah korban banjir belum terlaksana, namun upaya untuk pembuatan tembok-tembok dan beronjong-beronjong 
penahan tebing di sepanjang sungai Batang Merao Kota Sungai Penuh Sudah ada yang telah dilaksanakan.

5. Badan Penanggulangan Bencana Daerah Kota Sungai Penuh sudah berupaya dalam Penanggulangan Bencana Banjir di Sungai Batang Merao Kota Sungai Penuh dengan cara penanggulangan :

a. Pra bencana, yang dibuktikan dengan kegiatan kesiapasiagaan dan mitigasi, Seperti Sosialisasi dan Simulasi Bencana.

b. Saat bencana, yang dibuktikan dengan kegiatan Tanggap Darurat Bencana, seperti Anggota Tim Reaksi Cepat (TRC) selalu mendirikan posko bencana di tempat kejadian bencana, juga pemberian bantuan yang di butuhkan pada saat bencana seperti karung untuk mencegah meluapnya air Sungai Batang Merao dan bantuan logistik seperti mie instant, makanan kaleng, air dus dan lain-lain.

c. Pasca bencana, yang di buktikan dengan kegiatan Rehabilitasi dan Rekonstruksi, seperti pembangunan Beronjong dan Turap penahan tebing.

\section{Saran}

Berdasarkan kesimpulan sebagaimana yang telah dikemukakan diatas, maka penulis menyarankan kepada Badan Penanggulangan Bencana Daerah Kota Sungai Penuh untuk:

1. Meningkatkan sosialisasi dan simulasi disetiap desa yang rawan banjir agar ancaman banjir dapat dihilangkan atau diminimalisir.

2. Meningkatkan selalu pengetahuan bagi para pegawai dan anggota TRC tentang kebencanaan sehingga menciptakan Sumber Daya Manusia yang profesional.

3. Terus berupaya dalam pengadaan mobil dapur umum, ambulance dan penambahan tenda untuk posko bencana serta hunian darurat agar dapat terpenuhi sesuai kebutuhan.

4. Menganggarkan bantuan bahan bangunan untuk korban banjir dalam program kerja selanjutnya sehingga masyarakat korban banjir dapat terbantu.

5. Badan Penanggulangan Bencana Daerah Kota Sungai Penuh Supaya Bisa Melakukan Koordinasi Dengan Pemerintah Daerah Kabupaten Kerinci dan Provinsi Jambi dalam kegiatan menanggulangi Banjir di sungai Batang Merao, Sebab Sungai Batang Merao bukan hanya melintasi Kota Sungai Penuh saja tetapi juga melintasi Kabupaten Kerinci.

6. Badan Penanggulangan Bencana Daerah Kota Sungai Penuh supaya melibatkan SKPD terkait dalam penanggulangn bencana banjir seperti Dinas Pekerjaan Umum melalui bidang pengairannya untuk mengusulkan pembuatan tembok penahan banjir dikawasan Sungai Batang Merao tentunya yang telah dilakukan pengecekan lapangan dan dikaji oleh BPBD Kota Sungai Penuh daerah yang masih rawan terhadap bencana banjir.

\section{UCAPAN TERIMA KASIH}

Dalam kesempatan ini izin kan penulis mengucapkan terimakasih kepada kepada unsur pimpinan STIA NUSA Sungai Penuh yang telah mendukung penulis dalam pelaksanaan penelitian ini baik dukungan secara moril maupun materil. Ucapan terimakasih juga kami sampaikan kepada Ketua Lembaga Penelitian dan Pengabdian Masyarakat (LPPM) STIANUSA Sungai Penuh beserta seluruh Tim Editor yang telah bersedia untuk menerbitkan naskah artikel yang dimuat pada adisi ini. 


\section{DAFTAR PUSTAKA}

Alwi, Hasan, dkk. Kamus Besar Bahasa Indonesia. Balai Pustaka, Jakarta.

Arikunto, Suharsini. 2006. Prosedur Penelitian Suatu Pendekatan Praktik. RinekaCipta,Jakarta.

Bakornas PB, 2006. Panduan Pengenalan Karakteristik Bencana dan UpayaMigitasinya di Indonesia, Sat Bakornas PBP, Jakarta

Deni Hidayati, 2005. Panduan Siaga Berbasis Masyarakat. LIPI Press, Jakarta.

Djedje Abdul Aziz, S.H. dan Drs. Sigit Edi Surono. 2007. Sistem Administrasi Keuangan Negara I, Jakarta.

Faisal, 1990.Strategi dan Operasional penanggulangan. Penerbit Liberty, Jakarta.

Gottschalk, Louis, 1986. Mengerti Sejarah (terjemahan Nugroho Notosusanto).UI-Press, Jakarta.

Hariyanto, V Heru.2001. Motivasi dan Kesehatan Mental. Jurnal Anemia,Surabaya.

IDEP, 2007.Panduan Umum Penanggulangan Bencana Berbasis Masyarakat.Edisi ke-2. Yayasan IDEP, Bali.

Kartono, Kartini, 1980. Pemimpin dan Kepemimpinan. PT. Grafindo Persada,Jakarta.

Ligal, S, 2008. Pendekatan Pencegahan dan Penanggulangan Banjir.Jurnal.Dinamika TeknikSipil Volume 8. Jakarta.

Malo, Manase dan Sri Trisnoningtias, 1999.Metode Penelitian Masyarakat.PAU-Ilmu Sosial Universitas Indonesia, Jakarta.

Miles, Mathew. B. \&Huberman, 2001.Qualitatif data Analysis "terj. RohendiTjetjep, Analisis data Kualitatif. UI Pers, Jakarta.

Mistra, 2007.Antisipasi Rumah di Daerah Rawan Banjir. Penebar Swadaya,Depok

Moleong, Lexy J, 2006. Metodologi Penelitian Kualitatif. Rosda karya, Bandung.

Nurachman, 2007.Pemulihan Trauma: Panduan Praktis Pemulihan TraumaAkibat Bencana Alam. LPLSP3, Jakarta.

Poerwandari, Kristi, 2005. Psikologis Korban Pasca Bencana. Jurnal Perempuan,Jakarta.

Kodoatie dan Sjarief, 2009.Pengelolaan Bencana Terpadu. Nuansa Aulia,Bandung.

Rahayu S, dkk, 2009. Monitoring Air Di Daerah Aliran Sungai.WorldAgroforestry Centre-Southeast Asia Regional Office. Indonesia, Bogor.

Rohmat, Dede, 2009. Tipikal Kuantitas Iniltrasi Menurut Karakteristik Lahan.Bandung

Saru, Arifin, 2008. Studi model kebijakan mitigasi difabel korban bencana alam(studi kasus di kabupaten bentu).yogyakarta.

Soeladi, 2006.Manajemen Bencana Alam Tsunami. Sekretariat Bakornas,Jakarta.

Suharto, Edi. 2005. Membangun Masyarakat Memberdayakan Rakyat. RafiaAditama, Bandung.

Sugiyono, 2010. Metodologi Penelitian Kualitatif. Alfabeta, Bandung.

Warto, 2010.Ujicoba Pola Manajemen Penanggulangan Korban Bencana Alampada Era Otonomi

Daerah. Jakarta.

Undang-Undang Republik Indonesia Nomor 24 tahun 2007 tentangPenanggulangan Bencana.

Undang-undang Nomor 24 Tahun 2007 Tentang Penanggulangan Bencana.

Peraturan Pemerintah Nomor 22 Tahun 2008 Tentang pendanaan dan pengelolaan Bantuan Bencana.

Peraturan Daerah Kota Sungai Penuh Nomor 03 tahun 2010 tentang Badan Penanggulangan Bencana

Daerah Kota Sungai Penuh. 